\title{
Importance of Identification of Blood Group Sub-Types A1, A2, A1B and A2B For Blood Transfusion Safety
}

\author{
Amita Yadav*, Anita Gupta and Rakesh Sharma \\ Blood Bank, Indira Gandhi Mahila Evam Balya Chikitsalaya, Bhopal (MP) -462001 India
}

\begin{abstract}
Background: Karl Landsteiner, discovered ABO blood group system. In 1911.Von Dungern described two different A antigens based on reaction between $\mathrm{A}$ antigen on $\mathrm{RBC}$, anti-A and anti-A1. A1 and $\mathrm{A} 2$ are the major subtypes of blood group A and differ from each other both qualitatively and quantitatively. The cells of approximately $80 \%$ of all group A or AB individuals are A1 or A1B and $20 \%$ remaining are A2 or A2B or weaker subtypes. Polymorphisms in the genes may lead to diminished amounts of A or B antigens on red blood cells giving rise to subtypes. These subgroups can result in discrepancy in ABO blood typing which can lead to serious transfusion reactions. Our objective was to assess the importance of identification of these subtypes.
\end{abstract}

Methods: This was a prospective study of blood groups of donors in blood bank of Indira Gandhi Mahila Evam Balya Chikitsalaya, Bhopal (MP), India. The data of the subtypes of $\mathrm{A}$ and $\mathrm{AB}$ was analysed.

Result: Analysis of 720 blood donors was done. Out of 166 donors of A group, 151 (91.0\%) belonged to A1 subtype and only 15 (9.0\%) belonged to A2. Of 64 donors with group AB, 54 (84.37\%) belonged to A1B subtype and 10 (15.63\%) belonged to A2B. It was noted that A2 in $\mathrm{AB}$ blood-group, as $\mathrm{A} 2 \mathrm{~B}$, was more frequent in occurrence than presence of $\mathrm{A} 2$ as an A blood group.

Conclusion: By proper assessment of these subtypes and incorporating them in $\mathrm{ABO}$ typing, rare but dangerous transfusion reactions can be avoided.

Keywords: A1 A2 Sub-Types, Antigen, Blood Group, Donors, Transfusion Reactions

\section{Introduction}

During the year 1900, Karl Landsteiner at the University of Vienna, discovered that some blood transfusions were successful while others could be deadly. Landsteiner then discovered the ABO blood group system. He demonstrated that the serum of some people agglutinated the red cells of other. From these early experiments, he identified three types, called $\mathrm{A}, \mathrm{B}$ and $\mathrm{C}(\mathrm{C}$ was later to be re-named $\mathrm{O}$ for the German "Ohne", meaning "without", or "Zero", "null" in English). The fourth less frequent blood group AB, was discovered a year later. In 1930, Landsteiner received the Nobel Prize in physiology and medicine for his work. ${ }^{[1]}$

Weak subgroups of A can be defined as those of group A subjects whose erythrocytes give weaker reactions or are non-reactive serologically with anti-A antisera than do those of subjects with $\mathrm{A}_{2}$ red blood cells ${ }^{[2]} \mathrm{A} 1$ and $\mathrm{A} 2$ are the major subgroups of blood group A and they differ from each other both qualitatively and quantitatively. A1 red blood cells have about one million A antigen per cell. A2 red cells have only 250,000 A antigen per cells or one fourth the amount that A1 cells have. ${ }^{[3]}$

Subgroups weaker than A2 are not frequent, and are characterized by a decreasing number of A antigen sites on the RBCs and a reciprocal increase in $\mathrm{H}$ antigen activity. Other subgroups of A include Aint, A3, Ax, Aend, Am, and Ael are met only rarely in transfusion practice, and the last four cannot reliably be identified on the basis of blood typing tests alone. ${ }^{[4]}$

Red cells from people with A1 and A2 subgroups both react strongly with monoclonal anti-A reagents in direct agglutination tests. The distinction between these two subgroups is, therefore, made depending on the cells' reactivity with the lectin from Dolichos biflorus seeds. The D. biflorus lectin reacts specifically with cells of the A1 subgroup, and will thus agglutinate $\mathrm{A} 1$ but not $\mathrm{A} 2$ red cells. Anti-A1 antibody appears as an atypical cold agglutinin in the sera of $\mathrm{A} 2$ or $\mathrm{A} 2 \mathrm{~B}$ individuals who lack the corresponding antigen. In the majority of cases, subgroups of A result from the expression of an alternate weak allele present at the $\mathrm{ABO}$ loci. ${ }^{[5]}$

Prevalence of A subgroups varies from place to place and with race. The observed frequencies of A1 and A2 subtypes are generally compatible with the HardyWeinberg equilibrium for the Mendelian inheritance of the allelic A1 and A2 genes. ${ }^{[6]}$ However, in some populations, such as blacks and the Japanese, the frequency of the 
A2B phenotype is significantly higher than the expected frequency based on the frequency of the A2 phenotype. ${ }^{[7]}$

This antibody causes discrepancy between forward \& reverse $\mathrm{ABO}$ testing and incompatibility when cross matched with A1 and A1B cells.

\section{Materials and Methods}

This was a prospective study over a period of 8 months (October 2017-May 2018). Blood samples from 720 patients were typed in our blood bank . Blood grouping was done using the test tube technique. Forward or cell grouping was done using monoclonal antisera anti-A, anti-B, anti-AB and anti-D and in-house prepared pooled $\mathrm{A}$ cells, B cells and $\mathrm{O}$ cells. All the laboratory techniques were carried out according to the manufacturers' instructions. Blood groups were interpreted based on the agglutination pattern with forward and reverse grouping. In the presence of $\mathrm{A}$ or $\mathrm{B}$ antigens agglutination was observed with the corresponding antisera. The presence of circulating anti-A or anti-B antibodies was detected by reverse typing using pooled cells. Samples of group A and AB were further tested with anti-A1 lectin to classify them into A1, A2 and weak A subgroups. Whenever the agglutination was 4+ with anti-A antisera but negative with anti-A1 lectin, the sample was considered as A2 subgroup. A weak reaction with anti-A antisera on cell grouping along with a negative result with lectin was taken to signify a weak subgroup of $\mathrm{A} .{ }^{[8]} \mathrm{A}$ or $\mathrm{AB}$ group samples which showed agglutination with pooled A cells were tested with A1 cells to confirm the presence of anti-A1 antibodies. Data were analyzed. Descriptive statistics were used to estimate frequencies. The significance of differences in proportions was analyzed using the chi-square test. The study was conducted in compliance with the guidelines of the ethics committee of the institute.

\section{Result}

Out of 720 blood donors 230 donors who had either A or AB blood group were taken for this study. 166 blood donors had A blood group and 64 had AB blood group. Out of 166 'A' blood group donor, 151(91\%) had A1 subgroup while rest $15(09 \%)$ had A2 subgroup. Out of 64 AB blood group, $54(84.37 \%)$ had A1B subgroup and 10 (15.63\%) had A2B subgroup (Table No. 1)

Table No. 1: Number and percentage of $A$ and $A B$ Subgroup in present Study.

\begin{tabular}{|c|c|c|c|}
\hline Blood Group & Sub group & Number & Percentage \\
\hline A & A1 & 151 & $91.0 \%$ \\
\hline AB & A2 & 15 & $9.0 \%$ \\
\hline & A1B & 54 & $84.37 \%$ \\
\hline & A2B & 10 & $15.63 \%$ \\
\hline
\end{tabular}

Table No. 2: Percentage of A and AB Subgroup in Different Part of India.

\begin{tabular}{|l|c|c|c|c|}
\hline City & A1 & A2 & A1B & A2B \\
\hline Hubli, Karnataka $^{[1]]}$ & 98.9 & 1.1 & 89.7 & 10.3 \\
\hline Cuttack,Orissa $^{[12]}$ & 94.2 & 5.8 & 68.5 & 31.5 \\
\hline Gwalior,MP(13] $^{[13}$ & 92.0 & 8.0 & 91.4 & 8.6 \\
\hline $\begin{array}{l}\text { Bhopal,MP( Present } \\
\text { Study) }\end{array}$ & 91.0 & 9.0 & 84.37 & 15.63 \\
\hline
\end{tabular}

Table No. 3: Number and Percentage of A and AB Subgroup in Various Countries.

\begin{tabular}{|l|c|c|c|c|}
\hline Country (Sample Size) & A1 & A2 & A1B & A2B \\
\hline Sudan(100) ${ }^{[14]}$ & $71(93.42)$ & $5(6.58)$ & $22(91.67)$ & $2(8.33)$ \\
\hline Japan $(4540)^{[6]}$ & $3558(99.83)$ & $6(0.17)$ & $965(98.86)$ & $11(1.14)$ \\
\hline India ( Present Study) & $151(91.0)$ & $15(9.0)$ & $54(84.37)$ & $10(15.63)$ \\
\hline
\end{tabular}




\section{Discussion}

The blood group A can be sub-classified as A1, A2 and weak A subgroups (Ax, A3, Aend, etc.) based on red cell agglutinability and various serological reactions. ${ }^{[8]}$ As shown in the Table 1, the prevalence of $\mathrm{A} 2$ and $\mathrm{A} 2 \mathrm{~B}$ groups in our study was $9.0 \%$ and $15.63 \%$, respectively. Distribution of $\mathrm{A} \& \mathrm{AB}$ subgroups varies greatly among different population. Approximately $80 \%$ of Blood Group A or AB are classified as A1 or A1B the remaining $20 \%$ are either A2 or A2B. ${ }^{\text {[9] }}$ In 1911, Von Dungern described two different $\mathrm{A}$ antigens based on reaction between $\mathrm{A}$ antigen on RBC, anti-A and anti-A1. ${ }^{[10]}$ Classification into A1 and A2 phenotypes account for $99 \%$ of all group A individuals. In our study 230 blood samples were taken having blood group $A$ and $A B$ and have been tested for their subgroups i.e. A1, A2, A1B, and A2B. It was found that from total of 166 A group, 151 (91.0\%) were A1, 15 (9.0\%) were A2, and from $64 \mathrm{AB}$ blood group, $54(84.37 \%)$ were $\mathrm{A} 1 \mathrm{~B}$ and $10(15.63 \%)$ were A2B.

The study done in Southern India shows $98.9 \%$ of A1 and $1.1 \%$ of $\mathrm{A} 2$ while among $\mathrm{AB}$, it is $89.7 \% \mathrm{~A} 1 \mathrm{~B}$ and $10.3 \%$ A2B. Other studies done in India also shows, More than $90 \%$ of A1 but among AB it ranged from $68.5 \%$ to $91.4 \%$ of A1B and $31.5 \%$ to $8.6 \%$ of A2B. (Table No. 2)

In the studies done at International level in Sudan out of 76 cases of A, A1 was present in $93.42 \%$, A2 in $6.58 \%$ cases. Out of 24 cases of AB, A1B was present in $91.67 \%$ and A2B was present in $8.33 \% .{ }^{[14]}$ In Japan (Hiroshima) Out of 3564 cases of A, A1 was present in $99.83 \%$, A2 in $0.17 \%$ cases. Out of 976 cases of AB, A1B was present in $98.86 \%$ and $\mathrm{A} 2 \mathrm{~B}$ was present in $1.14 \% .{ }^{[6]}$ (Table No.3) Our study is similar to those in Blacks and Japanese, who showed more prevalence of A2B than A2 subgroup. ${ }^{[6,7]}$

The presence of strong B gene would suppress A1 antigen activity explaining to the high frequency of $\mathrm{A} 2 \mathrm{~B}$ in Black populations. ${ }^{[15]} \mathrm{A} 2$ and $\mathrm{A} 2 \mathrm{~B}$ are rare subgroups. But still they are important because anti-A1 antibodies occur in sera of A2 groups and more common in A2B subgroups ${ }^{[16]}$ and can be encountered during clinical practice ${ }^{[17]}$ causing difficulties in blood typing ${ }^{[18]}$, hemolytic transfusion reaction ${ }^{[19]}$ and complicate organs transplantation. ${ }^{[20]}$

\section{Conclusion}

By knowing prevalence of these subgroups in blood bank at tertiary care hospital, dangerous transfusion reactions occurring due to minor incompatibilities can be avoided. Though a molecular characterization of the subtypes would have been useful in this regard, so there is requirement of further studies with large sample number along with molecular categorization for safe and proper blood transfusion services which will lead to greater benefit of patients.

\section{Acknowledgements}

I would like to thank our in charge, co- workers and all the technical staff of our blood bank for their support to complete this work.

\section{References}

1. Farhud D, Marjan Z.A Brief History of Human Blood Groups. Iran J Publ Heal. 2013;42(1):1-6.

2. Cartron JP, Gerbal A, Hughes-Jones NC, et al. 'Weak A' phenotypes: relationship between red cell agglutinability and antigen site density. Immunology 1974; 27: 723-7.

3. Text book Principles \& practices of Transfusion Medicine Dr.(Prof.) R.N. Makroo.

4. Franchini M, Liumbruno GM ABO blood group: old dogma, new perspectives. ClinChem Lab Med 2013; 51(8): 15451553 .

5. Heier HE, Namork E, Calkoska Z, et al. Expression of A antigens on erythrocytes of weak blood Group A subgroups. Vox Sang1994; 66: 231-6.

6. Yoshida A, Dave V, Hamilton HB. Imbalance of blood group A subtypes and the existence of superactive B gene in Japanese in Hiroshima and Nagasaki. Am J Hum Genet 1988; 43(4):422-428.

7. Ogasawara K, Yabe R, Uchikawa M, et al. Different alleles cause an imbalance in $\mathrm{A} 2$ and $\mathrm{A} 2 \mathrm{~B}$ phenotypes of the ABO blood group. Vox Sang 1998; 74: 242-7.

8. Shastry S, Bhat S. Imbalance in A2 and A2B phenotype frequency of $\mathrm{ABO}$ group in South India. Blood Transfusion. 2010;8(4):267-270.

9. Mourant AE, Kope AC, Domaniewska K. The distribution of human blood groups and other polymorphisms. 2nd ed. New York, USA: Oxford University Press; 1977

10. Watkins, WB. The ABO blood group system: Historical background. Transfus. Med. 2001;11:243-265.

11. Giriyan SS, Agrawal A, Bajpai R, Nirala NK. A1 and A2 Sub-Types of Blood Group "A": A Reflection of their Prevalence in North Karnataka Region. Journal of Clinical and Diagnostic Research : JCDR. 2017;11(5):EC40-EC42.

12. Mahpatra S, Mishra D, Sahoo D: Study of prevalence of A2, A2B along with Major ABO Blood groups to minimize the transfusion reactions: 5: (3) IJSR March 2016, 189-190.

13. Sharma D C, Rai S, Iyenger S, Jain B: Prevalance and Distribution of $\mathrm{ABO}$ and Rh-D Antigens along with its subgroups \& Rare Types in Greater Gwalior Region (3) OJBD 2013, 69-73.

14. Ahmed M E, Nada Y A, Hala A M, Sulafa A H; Frequency of the A2- subgroup among blood group A and blood group among students of faculty of medicine and health sciences at Alimam Almahadi University, White Nile, Sudan. Hematol Transfus Int J 2015; 1(4):00022. 
15. Voak D, Lodge TW, Reed Jv. A possible explanation for the expression of A2B Phenotypes observed in some populations. Vox Sang 1970; 18: 471-4

16. Rudmann SV. Textbook of Blood Banking and Transfusion Medicine. 1st ed. WB Saunders, USA;1995. p. 73-75.

17. Chaudhari Surg Cdr CN, Surg Capt RN Misra, Col AK Nagpal. Transfusion in blood group A2B with anti A1 recipient. MJAFI. 2008;64:371-372.
18. Padmasri R, Urvashi B, Iyengar RS. A Rare Case of A2 +ve Blood group in an Obstetric emergency. J Clin Diagn Res. 2014;8(2):181-182.

19. Chaudhary R, Sonkar A. High titer immunizing anti-A1 in an A2 B patient resulting in hemolytic transfusion reaction. Transfusion Bulletin. 2004;12(2):2004-2008

20. Brecher ME, Moore SB, Reisner RK, Rakela J, Krom RA Delayed hemolysis resulting from anti-A1 after liver transplantation. Am J Clin Pathol 1989; 91(2): 232-258.

*Corresponding author:

Dr. Amita Yadav, Quarter No. F-4, Indira Gandhi Mahila Evam Balya Chikitsalaya Campus, Bhopal (MP) -462001 India

Phone: +919584408270

Email: amita.ritu@gmail.com

Financial or other Competing Interests: None. 